\title{
Aspirin dosage for the prevention of graft occlusion in people undergoing coronary surgery: a systematic review and meta-analysis
}

\begin{abstract}
Fares Alahdab, Ruba Zuhri Yafi ${ }^{1}$, Abdelkader Chaar², Ali Alrstom³, Muayad Alzuabi ${ }^{4}$, Omar Alhalabi $^{5}$, Somar Hasan ${ }^{6}$, Mahmoud

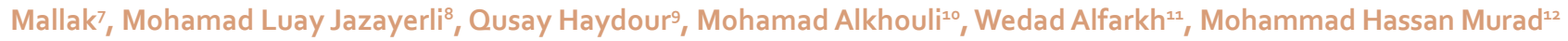
Evidence-based Practice Center, Mayo Clinic, Rochester, Michigan, USA, ${ }^{1}$ Faculty of Medicine, Damascus University, Damascus, Syrian Arab Republic, ${ }^{2}$ Department of Medicine, Yale New Haven Hospital, New Haven, Connecticut, USA, ${ }^{3}$ Department of Medicine, Damascus University, Almwasat Hospital, Damascus, Syrian Arab Republic, ${ }^{4}$ Department of Neurology, Medical University of South Carolina, Charleston, South Carolina, ${ }^{5}$ Division of Cancer Medicine, University of Texas MD Anderson Cancer Center, Houston, Texas, USA, ${ }^{6}$ Department of Ophthalmology, Jena University Hospital, Jena, Germany, ${ }^{7}$ Children's University Hospital, ${ }^{8}$ Faculty of Medicine, University of Damascus, Damascus, Syrian Arab Republic, ${ }^{9}$ Department of Internal Medicine, Cleveland Clinic Akron General, Akron, ${ }^{10}$ Department of Cardiovascular Medicine, Mayo Clinic, ${ }^{11}$ Department of Pathology, Baylor College of Medicine, ${ }^{12}$ Mayo Evidence-based Practice Center (EPC), Mayo Clinic, Rochester, Michigan, USA
\end{abstract}

\begin{tabular}{|c|}
\hline Access this article online \\
\hline Website: www.avicennajmed.com \\
\hline DOI: 10.4103/ajm.ajm_17_20 \\
\hline Quick Response Code: \\
\hline
\end{tabular}

\begin{abstract}
Background: Aspirin is almost always used after coronary artery bypass graft (CABG) surgery; however, it is unclear what optimal dose should be prescribed. In this systematic review, we evaluated the effects of high versus low-dose aspirin in patients after CABG. Methods: A comprehensive database search was conducted in several databases from date of inception until February 2018. There were no language restrictions. We included studies that compared different doses of aspirin in patients that had undergone CABG surgery. We included studies that evaluated patient-important outcomes (mortality, cardiovascular events, and gastrointestinal bleeding); and if not reported, we collected data on the surrogate outcome thromboxane B2 (TXB2). We collected relevant data and performed a meta-analysis. Results: We identified 5903 references, and after two levels of screening by two independent reviewers, we included three randomized controlled trials in the meta-analysis with a total number of 122 participants. Mean age of trial participants was 65.63 years, and $88.68 \%$ were male. We planned to analyze all possible clinical outcomes, including mortality, recurrence, and hospitalization. However, no clinical outcomes are reported by the literature. The surrogate biochemical outcome of serum TXB2 was the only outcome reported by the eligible studies. High-dose aspirin (162-325 mg once daily) achieved better suppression of TXB2 than low-dose aspirin (75-100 mg once daily) (mean difference [MD], $2.00 \mathrm{ng} / \mathrm{mL}, 95 \%$ confidence interval [Cl]: 0.72-3.32; participants = 122; studies $=3 ; 1^{2}=0 \%$ ). Conclusions: We found no clinical trials addressing any of the clinical outcomes of interest. High-dose aspirin was superior to low-dose aspirin in suppressing platelet function, a surrogate outcome. Trials evaluating clinical and patient-important outcomes are needed to better inform medical practice and fill this gap in clinical knowledge.
\end{abstract}

Key words: Aspirin, atherosclerosis, coronary artery bypass graft, myocardial infarction, review, systematic review

\section{BACKGROUND}

The long-term success of coronary artery bypass graft (CABG) surgery largely relies on the persistent patency of

Address for correspondence: Dr. Fares Alahdab,

Evidence-based Practice Center, Mayo Clinic,

Rochester, Minnesota, USA.

E-mail: fares.alahdab@gmail.com
This is an open access journal, and articles are distributed under the terms of the Creative Commons Attribution-NonCommercial-ShareAlike 4.0 License, which allows others to remix, tweak, and build upon the work non-commercially, as long as appropriate credit is given and the new creations are licensed under the identical terms.

For reprints contact: reprints@ @edknow.com

Cite this article as: Alahdab F, Zuhri Yafi R, Chaar A, Alrstom A, Alzuabi M, Alhalabi $\mathrm{O}$, et al. Aspirin dosage for the prevention of graft occlusion in people undergoing coronary surgery: A systematic review and meta-analysis. Avicenna J Med 2020;10:198-207. 
the graft conduits. Saphenous vein grafts (SVGs) have the benefits of being abundant and easy to harvest, but their long-term patency compared to the left internal mammary artery (LIMA) is poor. ${ }^{[1]}$ For vein grafts, generally, $15 \%-30 \%$ are occluded within 1 year after CABG, and about $50 \%$ of these occlusions happen in the first 2 weeks. ${ }^{[1]}$ However, after the first year post-CABG, the annual occlusion rate is $2 \%-$ $5 \%$. Ten years after the surgery, approximately one-third of the vein grafts that had been patent at 1 year remained patent and another third become occluded. ${ }^{[2]}$ Other studies have shown that $12 \%$ of vein grafts are occluded within 1 year, $25 \%$ within 5 years, and $50 \%$ within 12 years after $\mathrm{CABG},{ }^{[3]}$ and even more studies reported an incidence of one or more total SVG occlusions to be as high as $41 \%$ at 1 year after onpump CABG. ${ }^{[4-10]}$ This explains why $3 \%$ of participants need a repeat operation within 5 years, $10 \%$ within 10 years, and 25\% within 20 years. ${ }^{[11]}$ Hybrid revascularization (LIMA to left anterior descending [LAD], and percutaneous coronary intervention [PCI] to the other occluded coronaries) is thought to be the solution to the problem of high rates of vein graft failure. ${ }^{[12,13]}$ However, the utilization rates have been very disappointing, and vein grafts are still used for the majority of people. ${ }^{[14]}$ Data on the results of hybrid procedures have been inconsistent, unfortunately. ${ }^{[15]}$ This highlights the importance of continuing to search for the optimal strategy to improve vein graft latency.

Lack of aspirin (acetylsalicylic acid) prescribed at hospital discharge (discharge aspirin) was the strongest independent correlate of long-term mortality after CABG in the land mark SYNTAX trial. ${ }^{[16]}$ Platelet inhibition represents a therapeutic mainstay in treating people with CABG, and they routinely receive aspirin as a standard treatment for preventing occlusion and preserving bypass graft surgery benefits, ${ }^{[17]}$ and continue it indefinitely. ${ }^{[18]}$ Furthermore, early postoperative aspirin within $6 \mathrm{~h}$ following CABG has been reported to be the best approach for the prevention of vein graft occlusion. ${ }^{[19]}$ Platelet inhibition is associated with a reduced risk of death, reduced ischemic complications, and improved graft patency ${ }^{[20-23]}$ This desired effect of aspirin diminishes the later it is administered. ${ }^{[19]}$ Aspirin is the drug of choice for the prevention of SVG closure in the short term and is recommended for indefinite use following the procedure due to its benefit in secondary prevention of death and cardiac events in people with coronary artery disease $(\mathrm{CAD}) \cdot{ }^{\left[{ }^{[18]}\right.}$ Despite this benefit, its use for longer than 1 year following CABG does not seem to improve vein graft patency. ${ }^{[24]}$ Aspirin is effective in reducing further events in people with coronary heart disease; however, evidence is not conclusive as to which dose is optimal. ${ }^{[19]}$

Antiplatelet therapy with aspirin had a slight beneficial effect on the patency of peripheral bypass grafts. ${ }^{[25]}$ However, the debate on dosages of aspirin continues. Some studies showed that there is a lack of additional benefit with highdose aspirin but this was accompanied with an increased risk of bleeding. ${ }^{[26,27]}$ Residual platelet activity was lower in participants who received aspirin $325 \mathrm{mg}$ compared to participants who received aspirin $100 \mathrm{mg} .{ }^{[28]}$ Moreover, a single dose of aspirin $325 \mathrm{mg}$ on the first postoperative day may have a greater inhibitory effect on collagen-induced aggregation than a single dose of aspirin $100 \mathrm{mg}$. ${ }^{[29]}$

The uncertainty of the optimum dose of aspirin after CABG is the main reason why this review is important. We therefore aimed to evaluate the use of different dose regimens of aspirin to prevent graft occlusion in people who have undergone coronary artery bypass grafting.

\section{METHODS}

This systematic review and meta-analysis was conducted and reported in accordance with the Preferred Reporting Items for Systematic Reviews and Meta-Analyses (PRISMA) statement. ${ }^{[30]}$

\section{Criteria for considering studies for this review}

Weincluded all randomized controlled trials (RCTs) (irrespective of language or sample size) comparing different dosages of aspirin for the purpose of maintaining graft patency in people who have undergone CABG surgery. We excluded all quasirandomized studies, such as those allocating using alternate days of the week or surname of the participant, as they are not truly randomized and are more prone to bias. We did not include crossover trials. We also excluded trials that did not study aspirin as the sole therapy or trials not including a comparison group.

A given participant population was only used once; if the same population appeared in other trials, we included the article that provided the most complete follow-up data. We also excluded studies where one or more of the participant groups received another treatment, such as clopidogrel, because it would be difficult to adjust for the effects of the additional intervention.

We included trials that enrolled people who had undergone coronary artery surgery (both on- and off-pump, and including emergency and elective procedures) and had been placed on aspirin therapy after surgery. We included all trials of participants aged 18 years and older, of either gender, and in any clinical setting.

We included all studies comparing different dosages of aspirin in participants who have undergone coronary bypass surgery. 
We aimed to analyze the outcomes for different lengths of follow-up: up to 3 months, 6 months, 1 year, 5 years, and 10 years, if possible.

\section{Primary outcomes}

- Short-term postoperative cardiovascular-related mortality (i.e., within 30 days of the operation)

- Short-term postoperative all-cause mortality (i.e., within 30 days of the operation)

- Aspirin adverse effects:

o Minor adverse effects (e.g., gastritis)

o Major adverse effects (such as gastrointestinal bleeding, acute renal failure)

\section{Secondary outcomes}

- Failed on first CABG attempt

- Need for coronary intervention

- Recurrence of cardiovascular events (e.g., myocardial infarction $[\mathrm{MI}]$, stable, or unstable angina)

- Serum levels of thromboxane B2 (TXB2) as a measure of antithrombotic effects

- Heart failure

- Health-related quality of life (as defined by the individual trials)

- Health-related costs

\section{Search methods for identification of studies}

Electronic searches

We searched the following electronic databases: the Cochrane Central Register of Controlled Trials (CENTRAL), MEDLINE (Ovid), Embase (Ovid), and Web of Science (Thomson Reuters) from their inception till February 2018.

We used medical subject headings ( $\mathrm{MeSH}$ ) or equivalent and text word terms and imposed no language restrictions. We also searched the Clinical Trials database (www.clinicaltrials.gov) and the World Health Organization (WHO) International Clinical Trials Registry platform (ICTRP) (apps.who.int/ trialsearch/) for ongoing trials. Appendix 3 includes the search strategy for these two databases.

\section{Searching other resources}

We checked reference lists of reviews and retrieved articles for additional studies. We contacted experts in the field for unpublished and ongoing trials, and we contacted trial authors, where necessary, for any additional information.

\section{Data collection and analysis}

We performed the review and meta-analyses following the recommendations of Cochrane. ${ }^{[31]}$ We performed the analyses using Review Manager 5. ${ }^{[32]}$

\section{Selection of studies}

Two authors independently inspected each citation from the searches and identified relevant abstracts (FA, RZY, AC, AA, and MA). A third author inspected a random $20 \%$ sample of these citations to ensure reliability. Two authors obtained and inspected each full report of the abstracts that met the review criteria (FA, RZY, AC, AA, MA, and WA), in addition to citations that the authors disagreed on. A third author inspected a random $20 \%$ of these full reports to ensure reliable selection. Where it was not possible to resolve a disagreement by discussion, we attempted to contact the authors of the study for clarification. ${ }^{[31]}$

\section{Data extraction and management}

Two authors independently extracted data from each of the studies (FA and WA). We discussed and documented any disagreements. With remaining disagreements, a third author helped clarify issues, and we documented the final decisions. We extracted data presented only in graphs and figures, whenever possible, but only included them if two authors independently had the same result. If studies were multicenter, where possible, we extracted data relevant to each component center separately.

We used a standardized template of a data collection form to extract data on methods, participants, interventions, and outcomes.

\section{Assessment of risk of bias in included studies}

Working independently, two authors (FA and MA) assessed methodological risk of bias of included studies for adequacy of sequence generation, allocation concealment, blinding (participants, personnel, and outcome), drop-out rates (incomplete outcome data), analysis of intention to treat (ITT), selective outcome reporting, and other biases using the tool described in the Cochrane Handbook for Systematic Reviews of Interventions. ${ }^{[31]}$

We assessed and categorized the risk of bias in each domain and overall bias as the following:

- Low risk of bias: plausible bias unlikely to seriously alter the results

- High risk of bias: plausible bias that seriously weakens confidence in the results

- Unclear risk of bias: plausible bias that raises some doubt about the results

When any disagreement arose, we made the final decision by consensus, with the involvement of another author. We contacted authors of the studies when details about randomization or other characteristics of the trial were 
missing. We reported nonconcurrence in quality assessment, but when disputes arose as to which category a trial was to be allocated, we obtained resolution by discussion.

\section{Measures of treatment effect}

For binary outcomes (e.g., MI or no MI at follow-up), we had planned to calculate a standard estimation of the random-effects risk ratio (RR) and its $95 \%$ confidence interval (CI). However, none of the dichotomous outcomes were reported by the included studies, therefore, we had no such data.

For continuous outcomes (e.g., TXB2), we calculated the mean values and standard deviations for each intervention and comparison group. Whenever the continuous outcome measurement was similar enough to allow quantitative pooling, we used the mean difference (MD) and its $95 \% \mathrm{CI}$ to summarize the results.

We contacted the authors of all the trials, whenever we found missing data.

\section{Assessment of heterogeneity}

We considered all included studies without any comparison data to judge clinical and methodological heterogeneity. We inspected all studies for clearly outlying situations or people that we had not predicted and discussed them fully.

We visually inspected forest plots to identify trials with nonoverlapping CIs to suggest the possibility of statistical heterogeneity.

We investigated heterogeneity between studies by considering the $I^{2}$ statistic and the $\chi^{2} P$ value. The $I^{2}$ statistic provides an estimate of the percentage of inconsistency thought to be due to chance. ${ }^{[33]}$ The importance of the observed value of the $\mathrm{I}^{2}$ statistic depends on the magnitude and direction of effects, and the strength of evidence for heterogeneity (e.g., $P$ value from $\chi^{2}$ test, or a CI for the $\mathrm{I}^{2}$ statistic).

We interpreted an $\mathrm{I}^{2}$ statistic estimate of $50 \%$ or greater accompanied by a statistically significant $\chi^{2}$ statistic as evidence of substantial levels of heterogeneity, ${ }^{[33]}$ and explored reasons for heterogeneity. When inconsistency was substantial and we found clear reasons for this, we planned to present data separately.

\section{Assessment of reporting biases}

Owing to the small number of the included studies, we were not able to conduct the planned assessment of publication and reporting biases.

\section{Data synthesis}

We understand that there is no closed argument for preference for use of fixed-effect or random-effects models. The random-effects method incorporates an assumption that the different studies are estimating different, yet related, intervention effects. This often seems to be true, and the random-effects model takes into account differences between studies even if there is no statistically significant heterogeneity. However, there is a disadvantage to the random-effects model as it puts added weight onto small studies, which often are the most biased ones. ${ }^{[34]}$ Depending on the direction of effect, these studies can either inflate or deflate the effect size.

We analyzed data using a random-effects model and a fixed-effect model. In case of discrepancy between the two models, we reported both results. Otherwise, we only reported results from the random-effects model. We planned to analyze data according to the ITT principle and to present them as RR and risk difference with 95\% CI for dichotomous variables (did not apply as we had no dichotomous outcome data), and as mean values and standard deviations for continuous variables. We calculated and pooled the MDs across the included studies between the two groups of low vs. high aspirin dosage.

\section{RESULTS}

\section{Results of the search}

The flow diagram for study selection is shown in Figure 1. We initially identified 5903 references from the databases search and other sources to go through the abstract screening phase. After excluding 4031 ineligible studies, a total of 135 studies moved on to the full-text screening level. Eventually, we included six studies in the qualitative synthesis, and four in the quantitative synthesis (meta-analysis). No exclusion of any trial was made on the grounds of not reporting on an outcome of interest.

\section{Included studies}

None of the included studies reported any of the patient-important outcomes of interest we initially set out to evaluate. They did, however, report TXB2 levels, a surrogate outcome for platelet function, which we analyzed quantitatively.

One of the studies we included ${ }^{[35]}$ had an abstract that was published in $2013,{ }^{[36]}$ and a first version of the study was published in 2015. ${ }^{[37]}$ We chose to keep the 2013 and 2015 reports of this study in the review for informative purposes as they had different number of patients reported than the full paper published later. However, we did not include them 
in the quantitative analysis as to not count the same patients move than once.

We included three randomized controlled trials with a total number of patients of 122 . Mean age of trial participants across the included three trials was 65.63 years, and $88.67 \%$ were male. Table 1 described the included studies.

The three randomized trials we included aimed to evaluate the effects of different dosages of aspirin by measuring the serum TXB2 levels postoperatively. All studies also evaluated whether multiple-times-a-day aspirin regimen suppressed TXB2 better than a once-a-day regimen of aspirin. Specifically, the Paikin 2017 trial studied the different effects of $81 \mathrm{mg}$ once daily (OD), as compared to the $325 \mathrm{mg}$ OD and $162 \mathrm{mg}$ twice daily (BID). TXB2 was measured on postoperative day 4 in all of the three groups of patients. The patients in this single-center Canadian trial were undergoing elective or urgent $C A B G$ surgery with or without valve surgery.

The Ivert $2017^{[38]}$ trial evaluated the platelet-inhibition effects of $75 \mathrm{mg}$ OD as compared to $75 \mathrm{mg}$ BID and $160 \mathrm{mg}$ OD. TXB2 was measured 1 and 3 months postoperatively. This was also an open label parallel randomized trial of patients undergoing elective CABG only, therefore, all of them had stable angina pectoris.

Brambilla et al., ${ }^{[28]}$ on the contrary, evaluated the effect of two different doses (100 and $325 \mathrm{mg}$ OD) of aspirin on platelet function and TXB2 levels on postoperative day 5 .

\section{Excluded studies}

We made the decision to exclude 132 full-text articles due to several reasons: 35 due to an intervention that was not of interest, 36 due to a comparator not of interest, 31 due to a study design that was not of interest, 8 due to use of a second intervention, 12 due to outcomes that were not of interest, and 10 due to a patient population that was not of interest.

\section{Risk of bias in included studies}

The included studies had an overall low risk of bias. The only domain of the Cochrane tool for risk of bias assessment for RCTs that seemed of concern was relating to duration of follow-up. Although the studies seemed to have a complete enough follow-up, the duration of this follow-up was very short. For Ivert 2017, the surrogate outcome we evaluated (TXB2 level) was measured at 1 and 3 months postoperatively. For Paikin 2017, it was at postoperative day 4 . For a study by Brambilla $e t$ al., it was postoperative day 5 .

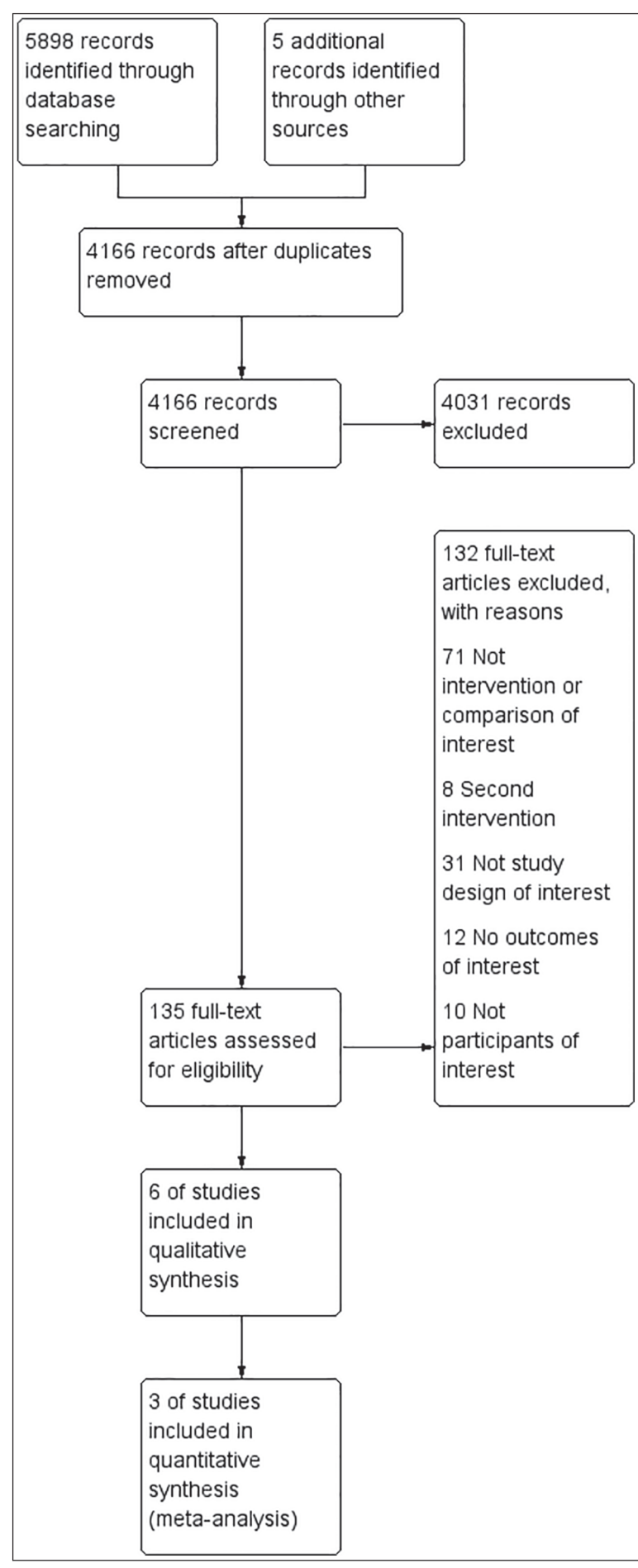

Figure 1: Flowchart of the screening process

Detailed assessment and a visual summary of the risk of bias in the included studies can be seen in Table 2 and Figure 2, respectively.

\section{Allocation (selection bias)}

The randomization procedure was clear, and allocation was concealed in the included studies. 
Alahdab, et al.: Aspirin dosage for prevention of graft occlusion

\begin{tabular}{|c|c|c|c|c|c|c|c|c|}
\hline Author & Year & $\begin{array}{l}\text { Study } \\
\text { design }\end{array}$ & Total, $\mathbf{N}$ & Aspirin dosages used & $\begin{array}{l}\text { Age in years, } \\
\text { mean (range) }\end{array}$ & Male, (\%) & Country & $\begin{array}{c}\text { TXB2 } \\
\text { measured at }\end{array}$ \\
\hline Paikin & 2015 & RCT & 110 & $81 \mathrm{mg}$ OD, $81 \mathrm{mg} 4 \times /$ day, $325 \mathrm{mg}$ OD & 65 (NR) & $82 \%$ & Canada & 4 days post-op \\
\hline Paikin & 2017 & $\mathrm{RCT}$ & 68 & $81 \mathrm{mg}$ OD, $162 \mathrm{mg}$ BID, $325 \mathrm{mg}$ OD & 65 (NR) & $88 \%$ & Canada & 4 days post-op \\
\hline Ivert & 2017 & $\mathrm{RCT}$ & $\begin{array}{c}75(42 \\
\text { included in } \\
\text { analysis) }\end{array}$ & $75 \mathrm{mg}$ OD, $75 \mathrm{mg}$ BID, I $60 \mathrm{mg}$ OD & 67.2 (NR) & $\begin{array}{c}41 \text { of } 42 \\
(98 \%)\end{array}$ & Sweden & $\begin{array}{l}I \text { and } 3 \text { months } \\
\text { post-op }\end{array}$ \\
\hline Brambilla & 2010 & RCT & 49 & $100 \mathrm{mg}$ OD, $325 \mathrm{mg}$ OD & 64.1 (NR) & 40 (81.3\%) & Italy & $\begin{array}{l}3 \text { and } 5 \text { days } \\
\text { post-op }\end{array}$ \\
\hline \multicolumn{9}{|c|}{ Abstract of Paikin 2013 later published in 2017 (above): } \\
\hline Paikin & 2013 & $\begin{array}{l}\text { RCT- } \\
\text { abstract }\end{array}$ & 100 & $81 \mathrm{mg}$ OD, $325 \mathrm{mg}$ OD, $81 \mathrm{mg} 4 \times /$ day & 65 (NR) & $84 \%$ & Canada & 4 days post-op \\
\hline
\end{tabular}

\begin{tabular}{|c|c|c|c|c|c|c|c|c|}
\hline Study ID & Year & $\begin{array}{l}\text { Selection of } \\
\text { patients }\end{array}$ & $\begin{array}{l}\text { Ascertainment } \\
\text { of exposure }\end{array}$ & $\begin{array}{l}\text { Control for } \\
\text { confounding }\end{array}$ & $\begin{array}{c}\text { Ascertainment of } \\
\text { outcome }\end{array}$ & $\begin{array}{l}\text { Follow-up long } \\
\text { enough }\end{array}$ & $\begin{array}{l}\text { Follow-up } \\
\text { complete } \\
\text { enough }\end{array}$ & $\begin{array}{c}\text { Conflicts } \\
\text { of } \\
\text { interest }\end{array}$ \\
\hline Paikin & 2015 & Low risk of bias & Low risk of bias & Low risk of bias & Low risk of bias & 4 days & Low risk of bias & $\begin{array}{l}\text { Low risk } \\
\text { of bias }\end{array}$ \\
\hline Paikin & 2017 & Low risk of bias & Low risk of bias & Low risk of bias & Low risk of bias & 4 days & Low risk of bias & $\begin{array}{l}\text { Low risk } \\
\text { of bias }\end{array}$ \\
\hline Ivert & 2017 & Low risk of bias & Low risk of bias & Low risk of bias & Low risk of bias & I and 3 months & High risk of bias & $\begin{array}{l}\text { Low risk } \\
\text { of bias }\end{array}$ \\
\hline Brambilla & 2010 & Low risk of bias & Low risk of bias & Low risk of bias & Low risk of bias & 5 days & High risk of bias & $\begin{array}{l}\text { Low risk } \\
\text { of bias }\end{array}$ \\
\hline \multicolumn{9}{|c|}{ Abstract of Paikin 2013 later published in 2017 (above): } \\
\hline Paikin & 2013 & Unclear (abstract) & Unclear (abstract) & Unclear (abstract) & Unclear (abstract) & 4 days & Unclear (abstract) & Unclear \\
\hline
\end{tabular}

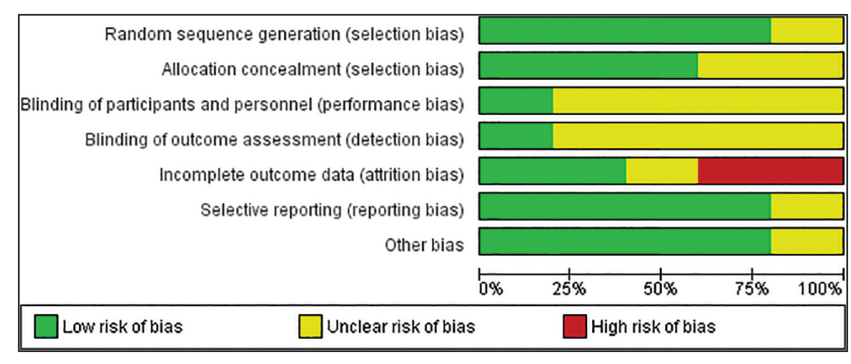

Figure 2: Risk of bias of the included studies

\section{Blinding (performance bias and detection bias)}

Blinding was present for participants, investigators, and staff in the included studies.

\section{Incomplete outcome data (attrition bias)}

There was no significant loss to follow-up in the included studies. The only exception was that of Brambilla et al., ${ }^{[28]}$ where only 49 participants' data were analyzed of 56 randomized.

\section{Selective reporting (reporting bias)}

No selective reporting was detected.

\section{Other potential sources of bias}

No other sources of bias were detected.

\section{Effects of interventions}

We pooled the MD of serum TXB2 levels comparing a low-dose aspirin (75-100 mg OD) and a high-dose aspirin
(162-325 mg OD). The analysis [Figure 3] showed a pooled $\mathrm{MD}$ of $2.00 \mathrm{ng} / \mathrm{mL}$ ( $95 \%$ CI: $0.72-3.23$, participants $=122$, studies $=3$ ) using the random-effects model. Interestingly, using the fixed-effects model [Figure 4], the pooled MD was also $2.00 \mathrm{ng} / \mathrm{dL}$ (95\% CI: 0.72-3.23, participants $=122$, studies $=3$ ). As the suppression of TXB2 leads to better antithrombotic function, this shows that the higher dose aspirin helps achieve better antithrombotic activity in patients who had undergone CABG. Detailed reporting of the serum TXB2 in the included studies can be found in Table 3.

As we had a very small number of included studies, we were not able to carry out any subgroup and sensitivity analyses. The outcomes of cardiovascular and all-cause mortality, aspirin adverse effects, failed first CABG attempt, need for coronary re-intervention, recurrence of cardiovascular events, heart failure, health-related quality of life, and healthrelated costs were not reported by any of the included studies. The small number of relevant studies in the literature also prevents the ability to conduct publication bias assessment.

\section{DISCUSSION}

\section{Summary of main results}

In this systematic review and meta-analysis, we evaluated the effects of low versus high dose of aspirin postoperatively in patients who have undergone CABG. We found that highdose aspirin (160-325 mg OD) was superior to low-dose 


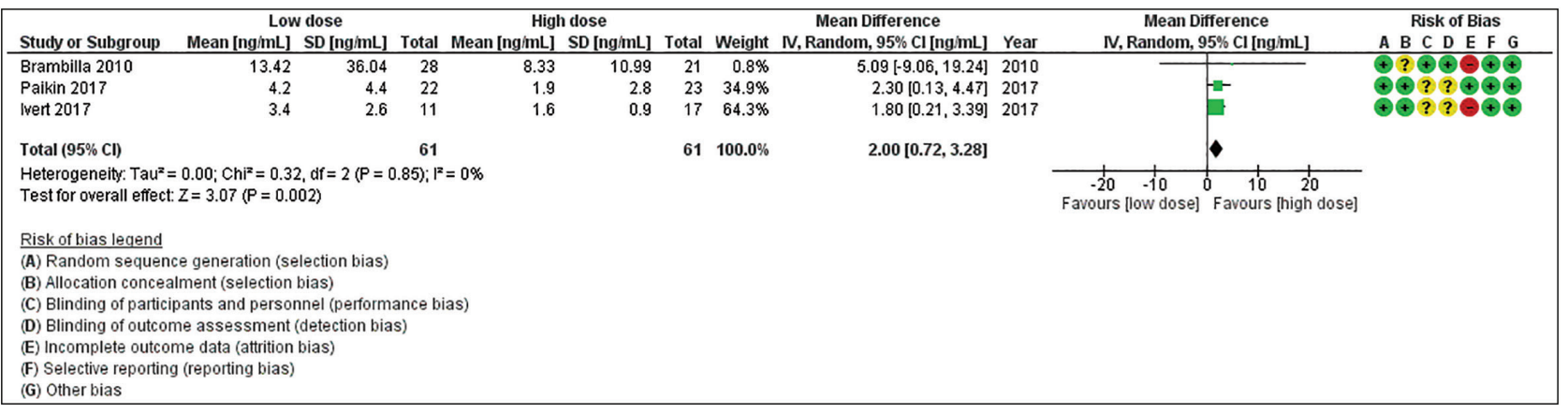

Figure 3: Pooling the thromboxane B2 levels across the included studies using the random-effects model

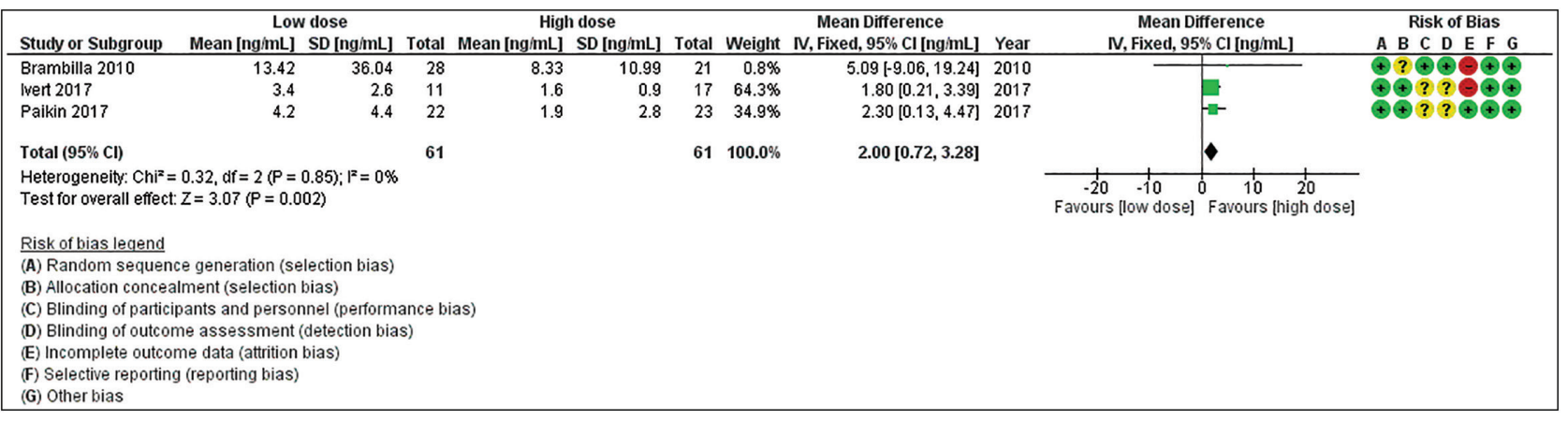

Figure 4: Pooling the thromboxane B2 levels across the included studies using the fixed effects model

aspirin (75-100 mg OD) in suppressing serum TXB2 by $2.00 \mathrm{ng} / \mathrm{mL}$ (95\% CI: $0.72-3.23$ ). As this is a surrogate biochemical outcome, it is unclear if this significant biochemical difference translates into an important clinical difference in any of the clinical outcomes we had set out to evaluate. When faced with uncertainty about a surrogate outcome, it is suggested to investigate the association between the surrogate and clinical outcomes. ${ }^{[39]}$ It has been shown that serum TXB2 was an independent risk factor for vein graft thrombosis after CABG surgery. ${ }^{[5]}$ Therefore, it is plausible that high-dose aspirin may be more protective.

\section{Overall completeness and applicability of evidence}

None of the identified studies in the literature reported any clinical outcomes of interest. Future studies need to focus on relevant and patient-important outcomes to better guide medical care for patients undergoing CABG. Also, the outcome of serum TXB2 was measured at different times by Ivert 2017 ( 1 and 3 months postoperatively) as compared to Paikin 2017 (fourth postoperative day) and Brambilla 2010 (fifth postoperative day). This could be another factor for better consistency in the methodology of outcome reporting for future studies. The patient samples of the included studies comprised an overwhelming male majority (89\%). This limits the generalizability of the findings to all patients undergoing CABG. Therefore, future studies should attempt to capture more balanced and representative samples.

\section{Quality of the evidence}

The quality of this evidence, however, is low. This was mainly due to the indirectness of the outcome measurements (TXB2 is a surrogate outcome) and heterogeneity in the timing of outcome measurement.

\section{Potential biases in the review process}

The main challenge we faced in this systematic review was the lack of evidence to adequately answer this question. None of the clinical outcomes we had set out to evaluate were reported in this body of literature at this point. Although reluctant, we had no other choice but to evaluate a surrogate biochemical outcome that was reported by the included studies. Surrogate and biochemical outcomes have their own inherent limitations of insufficiently informing medical practice and patients' goals of medical care. It is important to note that although this meta-analysis found a statistically meaningful MD in TXB2 levels between the low- and highdose aspirin after CABG, it is unlikely that this translates to a clinically meaningful difference. Additionally, although three of the included trials had evaluated the serum TXB2 levels on the fourth and fifth postoperative day, the third one evaluated it 1 and 3 months postoperatively. Although the results were not very different, but this casted doubt on the validity of pooling this study with the other two. One other limitation was the very small number of studies that were found. We interpreted the findings in light of these limitations. 


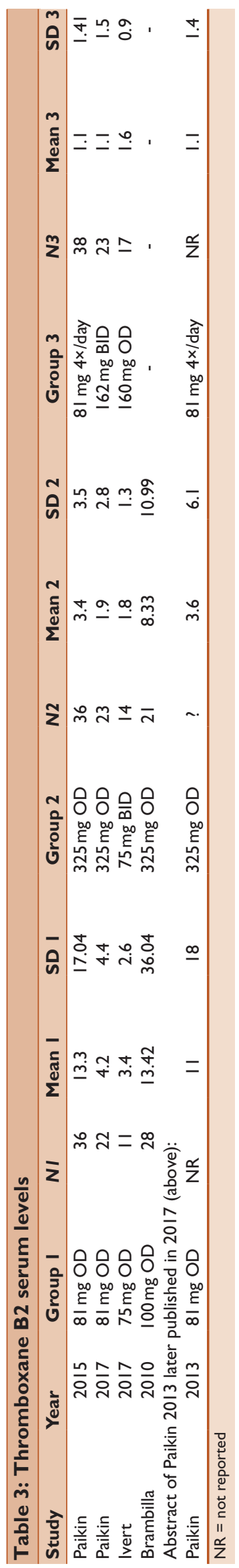

Agreements and disagreements with other studies or reviews

Significant risk factors for SVG thrombosis within 6 months of CABG surgery in people taking postoperative aspirin include small target vessel diameter, female gender, and low mean graft blood flow. ${ }^{[40]}$ Aspirin inhibits platelet activation by irreversibly acetylating platelet COX-1 and preventing the formation of thromboxane A2. Although aspirin has a half-life of approximately $20 \mathrm{~min}$, it produces almost complete inhibition of thromboxane A2 synthesis for $24 \mathrm{~h}$ when given once daily. ${ }^{[41]}$ In most patients receiving chronic once-daily aspirin therapy, platelet COX-1 activity is restored at a rate of approximately $10 \%$ per day, reflecting the 10-day platelet life span and the entry into the circulation of $10 \%$ of newly formed platelets. TXB2 is the stable metabolite of thromboxane A2 and arachidonate-induced platelet aggregation.

The 2011 American College of Cardiology (ACC)/American Heart Association (AHA) guidelines recommend that every person receives daily aspirin therapy after CABG (Class I indication). ${ }^{[18]}$ The 2012 American College of Chest Physicians (ACCP) guidelines on the primary and secondary prevention of cardiovascular disease also stated that people who undergo CABG should be started on aspirin and it should be continued indefinitely. ${ }^{[42]}$ Several studies assessed whether early treatment with aspirin inhibits platelet aggregation, has an effect on graft patency, or improves survival after coronary bypass surgery. Many of these studies have showed that early use of aspirin after CABG reduces the risk of death and ischemic complications. ${ }^{[21,43-45]}$ However, the guideline and many of the studies took no account of the wide variation in aspirin doses (from 75 to $325 \mathrm{mg}$ ). As a result, low-dose aspirin (75 to $150 \mathrm{mg}$ ) is usually prescribed despite the lack of direct comparison with medium- or high-dose regimens. ${ }^{[46]}$

There have been many advances in surgical techniques, interventional cardiovascular, and medical care for patients with CAD, particularly after CABG surgery. Furthermore, the use of aspirin, with or without other antiplatelets, has become routine practice for patients after CABG. However, it is still unclear what optimal aspirin dose should be prescribed to these patients postoperatively. With long-term success of this surgical intervention relying on graft patency, finding the aspirin dose most effective to achieve best clinical outcomes is paramount. Very little evidence exists to fill this gap, unfortunately. Clinical trials evaluating different dosages of aspirin after CABG that are evaluating clinical and patient-important outcomes are needed to fill this gap in knowledge to better inform medical practice. 


\section{AUTHORS' CONCLUSIONS}

\section{Implications for practice}

High-dose aspirin (160-325 mg OD) is superior to low dose (75-100 mg OD) in suppressing serum TXB2 levels, therefore, achieving better postoperative antithrombotic function for patients undergoing CABG.

\section{Implications for research}

Clinical trials evaluating different dosages of aspirin after CABG that are evaluating clinical and patient-important outcomes are needed to fill this gap in knowledge and to better inform medical practice.

\section{Financial support and sponsorship}

Nil.

\section{Conflicts of interest}

There are no conflicts of interest.

\section{REFERENCES}

1. Cooper GJ, Underwood MJ, Deverall PB. Arterial and venous conduits for coronary artery bypass. A current review. Eur J Cardiothorac Surg 1996;10:129-40.

2. Bourassa MG. Long-term vein graft patency. Curr Opin Cardiol 1994;9:685-91.

3. FitzGibbon GM, Kafka HP, Leach AJ, Burton JR. Interventions for coronary stenosis-a Canadian experience of 30 revolutionary years. Canadian J Cardiol 1996;12:893-900.

4. Alexander JH, Hafley G, Harrington RA, Peterson ED, Ferguson TB $\mathrm{Jr}$, Lorenz TJ, et al.; PREVENT IV Investigators. Efficacy and safety of edifoligide, an E2F transcription factor decoy, for prevention of vein graft failure following coronary artery bypass graft surgery: PREVENT IV: A randomized controlled trial. JAMA 2005;294:2446-54.

5. Gluckman TJ, McLean RC, Schulman SP, Kickler TS, Shapiro EP, Conte JV, et al. Effects of aspirin responsiveness and platelet reactivity on early vein graft thrombosis after coronary artery bypass graft surgery. J Am Coll Cardiol 2011;57:1069-77.

6. Goldman S, Zadina K, Moritz T, Ovitt T, Sethi G, Copeland JG, et al.; VA Cooperative Study Group \#207/297/364. Long-term patency of saphenous vein and left internal mammary artery grafts after coronary artery bypass surgery: Results from a department of veterans affairs cooperative study. J Am Coll Cardiol 2004;44:2149-56.

7. Halabi AR, Alexander JH, Shaw LK, Lorenz TJ, Liao L, Kong DF, et al. Relation of early saphenous vein graft failure to outcomes following coronary artery bypass surgery. Am J Cardiol 2005;96:1254-9.

8. Khot UN, Friedman DT, Pettersson G, Smedira NG, Li J, Ellis SG. Radial artery bypass grafts have an increased occurrence of angiographically severe stenosis and occlusion compared with left internal mammary arteries and saphenous vein grafts. Circulation 2004;109:2086-91.

9. Shroyer AL, Grover FL, Hattler B, Collins JF, McDonald GO, Kozora E, et al.; Veterans Affairs Randomized On/Off Bypass (ROOBY) Study Group. On-pump versus off-pump coronary-artery bypass surgery. $\mathrm{N}$ Engl J Med 2009;361:1827-37.

10. Widimsky P, Straka Z, Stros P, Jirasek K, Dvorak J, Votava J, et al. Oneyear coronary bypass graft patency: A randomized comparison between off-pump and on-pump surgery angiographic results of the PRAGUE-4 trial. Circulation 2004;110:3418-23.
11. Cohn LH. Cardiac Surgery in the Adult. New York: McGraw-Hill Medical; 2008.

12. Harskamp RE, Vassiliades TA, Mehta RH, de Winter RJ, Lopes RD, Xian Y, et al. Comparative effectiveness of hybrid coronary revascularization vs. coronary artery bypass grafting. J Am Coll Surg 2015;221:326-34.e1.

13. Panoulas VF, Colombo A, Margonato A, Maisano F. Hybrid coronary revascularization: Promising, but yet to take off. J Am Coll Cardiol 2015;65:85-97.

14. Shannon J, Colombo A, Alfieri O. Do hybrid procedures have proven clinical utility and are they the wave of the future?: Hybrid procedures have proven clinical utility and are the wave of the future. Circulation 2012;125:2492-503; discussion 2503.

15. Modrau IS, Holm NR, Mæng M, Bøtker HE, Christiansen EH, Kristensen SD, et al.; Hybrid Coronary Revascularization Study Group. One-year clinical and angiographic results of hybrid coronary revascularization. J Thorac Cardiovasc Surg 2015;150:1181-6.

16. Farooq V, Serruys PW, Bourantas C, Vranckx P, Diletti R, Garcia Garcia HM, et al. Incidence and multivariable correlates of long-term mortality in patients treated with surgical or percutaneous revascularization in the synergy between percutaneous coronary intervention with taxus and cardiac surgery (SYNTAX) trial. Eur Heart J 2012;33:3105-13.

17. Gavaghan TP, Gebski V, Baron DW. Immediate postoperative aspirin improves vein graft patency early and late after coronary artery bypass graft surgery. A placebo-controlled, randomized study. Circulation 1991;83:1526-33.

18. Hillis LD, Smith PK, Anderson JL, Bittl JA, Bridges CR, Byrne JG, et al.; American College of Cardiology Foundation; American Heart Association Task Force on Practice Guidelines; American Association for Thoracic Surgery; Society of Cardiovascular Anesthesiologists; Society of Thoracic Surgeons. 2011 ACCF/AHA guideline for coronary artery bypass graft surgery. A report of the American College of Cardiology Foundation/American Heart Association Task Force on practice guidelines. Developed in collaboration with the American Association for Thoracic Surgery, Society of Cardiovascular Anesthesiologists, and Society of Thoracic Surgeons. J Am Coll Cardiol 2011;58:e123-210.

19. Gukop P, Gutman N, Bilkhu R, Karapanagiotidis GT. Who might benefit from early aspirin after coronary artery surgery? Interact Cardiovasc Thorac Surg 2014;19:505-11.

20. Karzai W, Priebe HJ. Aspirin and mortality from coronary bypass surgery. N Engl J Med 2003;348:1057-9; author reply 1057-9.

21. Mangano DT. Aspirin and mortality from coronary bypass surgery, Multicenter Study of Perioperative Ischemia Research Group. N Engl J Med 2002;347:1309-17.

22. Patel JH, Stoner JA, Owora A, Mathew ST, Thadani U. Evidence for using clopidogrel alone or in addition to aspirin in post coronary artery bypass surgery patients. Am J Cardiol 2009;103:1687-93.

23. Stein PD, Schünemann HJ, Dalen JE, Gutterman D. Antithrombotic therapy in patients with saphenous vein and internal mammary artery bypass grafts: The seventh ACCP conference on antithrombotic and thrombolytic therapy. Chest 2004;126:600-8S.

24. Goldman S, Copeland J, Moritz T, Henderson W, Zadina K, Ovitt T, et al. Long-term graft patency (3 years) after coronary artery surgery. Effects of aspirin: Results of a VA cooperative study. Circulation 1994;89:1138-43.

25. Brown J, Lethaby A, Maxwell H, Wawrzyniak AJ, Prins MH. Antiplatelet agents for preventing thrombosis after peripheral arterial bypass surgery. Cochrane Database Syst Rev 2008:CD000535.

26. Mehta SR, Bassand JP, Chrolavicius S, Diaz R, Eikelboom JW, Fox KAA, et al. Dose comparisons of clopidogrel and aspirin in acute coronary syndromes. N Engl J Med 2010;10:930-42.

27. Peters RJ, Mehta SR, Fox KA, Zhao F, Lewis BS, Kopecky SL, et al.; Clopidogrel in Unstable angina to prevent Recurrent Events (CURE) Trial Investigators. Effects of aspirin dose when used alone or in combination with clopidogrel in patients with acute coronary syndromes: Observations from the Clopidogrel in Unstable angina to prevent Recurrent Events (CURE) study. Circulation 2003;108:1682-7. 
28. Brambilla M, Parolari A, Camera M, Colli S, Eligini S, Centenaro C, et al. Effect of two doses of aspirin on thromboxane biosynthesis and platelet function in patients undergoing coronary surgery. Thromb Haemost 2010;103:516-24.

29. Cornelissen J, Kirtland S, Lim E, Goddard M, Bellm S, Sheridan K, et al. Biological efficacy of low against medium dose aspirin regimen after coronary surgery: Analysis of platelet function. Thromb Haemost 2006;95:476-82.

30. Moher D, Liberati A, Tetzlaff J, Altman DG; PRISMA Group. Preferred reporting items for systematic reviews and meta-analyses: The PRISMA statement. PLoS Med 2009;6:e1000097.

31. Higgins JPT, Green S. Cochrane Handbook for Systematic Reviews of Interventions Version 5.1.0 [updated March 2011]. The Cochrane Collaboration, 2011. Available from: www.cochrane-handbook.org. [Last accessed on 2019 Nov 15].

32. Review Manager (RevMan). Copenhagen, Denmark: The Nordic Cochrane Centre, The Cochrane Collaboration; 2014.

33. Higgins JP, Thompson SG, Deeks JJ, Altman DG. Measuring inconsistency in meta-analyses. BMJ 2003;327:557-60.

34. Sterne JAC, Egger M, Moher D. Chapter 10: Addressing reporting biases. In: Higgins JPT, Green S, editors. Cochrane Handbook for Systematic Reviews of Interventions Version 5.1.0 [updated March 2011]. The Cochrane Collaboration; 2011. Available from: www.cochranehandbook.org. [Last accessed on 2019 Nov 15].

35. Paikin JS, Hirsh J, Ginsberg JS, Weitz JI, Chan NC, Whitlock RP, et al. Once versus twice daily aspirin after coronary bypass surgery: A randomized trial. J Thromb Haemost 2017;15:889-96.

36. Paikin JS, Eikelboom JW, Whitlock RP, Ginsberg JS, Weitz GPare JI, Hirsh J. Randomized trial to examine the effect of ASA dose or ASA dosing frequency on ASA resistance after coronary artery bypass graft surgery. Eur Heart J 2013;34:P234.

37. Paikin JS, Hirsh J, Ginsberg JS, Weitz JI, Chan NC, Whitlock RP, et al. Multiple daily doses of acetyl-salicylic acid (ASA) overcome reduced platelet response to once-daily ASA after coronary artery bypass graft surgery: A pilot randomized controlled trial. J Thromb Haemost 2015;13:448-56.
38. Ivert T, Dalén M, Ander C, Stålesen R, Näsman P, Lordkipanidzé M, et al. Platelet function one and three months after coronary bypass surgery in relation to once or twice daily dosing of acetylsalicylic acid. Thromb Res 2017;149:64-9.

39. Dobler CC, Morgan RL, Falck-Ytter Y, Montori VM, Murad MH. Assessing the validity of surrogate endpoints in the context of a controversy about the measurement of effectiveness of hepatitis $\mathrm{C}$ virus treatment. BMJ Evid Based Med 2018;23:50-3.

40. McLean RC, Nazarian SM, Gluckman TJ, Schulman SP, Thiemann DR, Shapiro EP, et al. Relative importance of patient, procedural and anatomic risk factors for early vein graft thrombosis after coronary artery bypass graft surgery. J Cardiovasc Surg (Torino) 2011;52: 877-85.

41. Patrono C, García Rodríguez LA, Landolfi R, Baigent C. Low-dose aspirin for the prevention of atherothrombosis. N Engl J Med 2005;353:2373-83.

42. Vandvik PO, Lincoff AM, Gore JM, Gutterman DD, Sonnenberg FA, Alonso-Coello $\mathrm{P}$, et al. Primary and secondary prevention of cardiovascular disease: Antithrombotic therapy and prevention of thrombosis, 9th ed: American college of chest physicians evidencebased clinical practice guidelines. Chest 2012;141:e637-68S.

43. Antiplatelet Trialists Collaboration. Collaborative overview of randomized trials of antiplatelet therapy. 2. Maintenance of vascular graft or arterial patency by antiplatelet therapy. BMJ 1994;308: 159-68.

44. Fremes SE, Levinton C, Naylor CD, Chen E, Christakis GT, Goldman BS. Optimal antithrombotic therapy following aortocoronary bypass: A meta-analysis. Eur J Cardiothorac Surg 1993;7:169-80.

45. Henderson WG, Goldman S, Copeland JG, Moritz TE, Harker LA. Antiplatelet or anticoagulant therapy after coronary artery bypass surgery. A meta-analysis of clinical trials. Ann Intern Med 1989;111:743-50.

46. Lim E, Ali Z, Ali A, Routledge T, Edmonds L, Altman DG, et al. Indirect comparison meta-analysis of aspirin therapy after coronary surgery. BMJ 2003;327:1309. 